\title{
Effect of flocculation and/or adsorption as pretreatment on the critical flux of crossflow microfiltration
}

\author{
W. S. Guo, S. Vigneswaran ${ }^{*}$, H. H. Ngo \\ Faculty of Engineering, University of Technology, Sydney, \\ PO Box 123, Broadway, NSW 2007, Australia \\ Tel: +61 (2) 95142641, Fax: + 61(2) 95142633, Email: s.vigneswaran@uts.edu.au
}

\begin{abstract}
This study aims at identifying the effect of pretreatment such as flocculation and/or adsorption on the performance of crossflow microfiltration (CFMF). The CFMF performance was studied in terms of critical flux. The results indicated that (i) flocculation alone as pretreatment could remove effectively the large molecular weight organic matter from 30,000 to 60,000 daltons; (ii) flocculation together with adsorption as pretreatment to the CFMF could enable to remove both of large and small molecular weight organics; (iii) flocculation as pretreatment was significantly better than adsorption in improving the critical flux; (iv) the critical flux was increased from $100 \mathrm{~L} / \mathrm{m}^{2} . \mathrm{h}$ to $520 \mathrm{~L} / \mathrm{m}^{2}$.h when flocculation-adsorption was applied. The critical flux in long term experiments was as same as that of the short-term experiments. However, the critical flux slightly decreased $(5 \%)$ in long term experiments compared to the short term operation with flocculation and adsorption as pretreatment.
\end{abstract}

Keywords: Crossflow microfiltration (CFMF); Critical flux; Wastewater treatment; Transmembrane pressure (TMP)

\section{Introduction}

Filtration flux stability is a significant component for application and evaluation of any pressure-driven membrane process. In wastewater treatment, the permeate flux of CFMF declines to the value which is far below the clean water filtration flux due to membrane fouling. The occurrence of this fouling affects the performance of the membrane either by deposition of a layer onto the membrane surface which introduces additional resistance to permeate flow, or by blockage or partial blockage of the pores which changes the effective pore size distribution [1].

* Corresponding author 
A number studies have been conducted to understand and minimize membrane clogging in order to make the membrane process more competitive. These studies can be classified into three broad categories, namely, hydrodynamic (changing flow regime across the membrane surface), surface modification (changing the surface/foulants affinity) and regular cleaning. The concept of the critical flux was introduced in the mid 1990's with a number of theoretical and experimental evidences. The critical flux hypothesis for MF is that on start-up there exists a flux below which a decline of flux with time does not occur; above it fouling is observed [1]. This flux is termed as critical flux and its value depends on the hydrodynamics and also on the particle size and their surface and chemical characteristics [2].

Vigneswaran et al. [3] experimentally compared three different methods of determining the critical flux from their constant-rate CFMF measurements,

1. Based on the increase in TMP: the critical flux is the flux below which there is no presence of TMP increase in resistance.

2. Based on particle mass balance: the critical flux is calculated from the rate of particle deposition at membrane surface. The highest flux value at which no particles deposition is observed is considered as critical flux.

3. Based on direct observation through microscope (DOTM): Li et al. [4] and Kwon [5] observed from a series of DOTM experiments that there are three stages of particles deposition on membranes - no approach of particles near the membrane surface, temporary deposition and permanent deposition. The minimum flux leading to permanent deposition of particles is defined as critical flux based on DOTM.

Application of membrane processes to water and wastewater treatment requires lower investment and operation costs. One of the ways of limiting operation costs is to operate at a constant filtration flux below the critical flux. However, due to the presence of colloids and soluble organics in most raw waters and in secondary treated wastewater, the critical flux will be very low. Operating at a low critical flux requires a large membrane area, thus a higher investment cost. The critical flux can be increased by modifying hydrodynamic conditions (e.g. high shear stress), but this results in higher energy consumption and higher operation cost. A pretreatment prior to the application of CFMF may be another option to increase the critical flux. Adsorption and flocculation can be suitable pretreatment methods. Therefore, the influence of additives for modifying the colloidal fraction of the organic matter by using flocculants or entrapping the organic solutes on to adsorbents has to be evaluated. An appropriate pretreatment will not only enhance the permeate flux but also improve the removal of dissolved organic matter. Basically, the pretreatment aims to reduce the loading of dissolved organic matter (DOM) on CFMF. Flocculation is one of the pretreatment methods that can improve the permeate flux of CFMF and remove particles and colloids. The flocculation enables to achieve three objectives: eliminating the penetration of colloidal particles into the membrane pores, increasing the critical flux and modifying the characteristics of the deposit [6]. Adsorption is another pretreatment method which can remove dissolved organic matter, thereby reducing the membrane fouling. 
In this study, critical flux based on the increase in TMP was used to assess the importance of flocculation and/or adsorption as pretreatment.

\section{Experimental}

A series of short- and long-term experiments was conducted using a synthetic wastewater contains persisting (less biodegradable) organic compounds (Table 1). This synthetic wastewater represents the biologically treated sewage effluent [7]. The Total organic carbon (TOC) of the synthetic wastewater is between $3.8-4.2 \mathrm{mg} / \mathrm{L}$ and $\mathrm{pH}$ is between 7.6-7.7.

Table 1

Constituents of the Synthetic Wastewater

\begin{tabular}{cc}
\hline Compounds & Weight $(\mathbf{m g} / \mathbf{L})$ \\
\hline Beef Extract & 1.8 \\
Peptone & 2.7 \\
Humic acid & 4.2 \\
Tannic acid & 4.2 \\
(Sodium) lignin sulfonate & 2.4 \\
Sodium lauryle sulphate & 0.94 \\
Acacia gum powder & 4.7 \\
Arabic acid (polysaccharide) & 5 \\
$\left(\mathrm{NH}_{4}\right)_{2} \mathrm{SO}_{4}$ & 7.1 \\
$\mathrm{KH}_{2} \mathrm{PO}_{4}$ & 7.0 \\
$\mathrm{NH}_{4} \mathrm{HCO}_{3}$ & 19.8 \\
$\mathrm{MgSO}_{4} \cdot 3 \mathrm{H}_{2} \mathrm{O}$ & 0.71 \\
\hline
\end{tabular}

\subsection{Pretreatment}

Adsorption and flocculation tests were conducted using a lab-scale batch reactor equipped with mechanical stirrers. Powdered activated carbon (PAC) was used as adsorbent. The characteristics of powdered activated carbon (PAC) used is shown in Table 2. The adsorption capacity of PAC for this synthetic wastewater is 0.00567 $\mathrm{g}_{\text {(TOC) }} / \mathrm{g}_{(\mathrm{PAC})}$ (Based on the equilibrium experiments' results). Ferric chloride $\left(\mathrm{FeCl}_{3}\right)$ was used as flocculant because it is more effective than alum in removing TOC and also can remove small moleculare weight (MW) organic matter through complexation mechanism [8]. The treated wastewater either from adsorption or flocculation process were settled down first. Their supernatant was used as the influent for CFMF experiments. 
Table 2

Characteristics of powdered activated carbon (PAC) used

\begin{tabular}{cc}
\hline Specification & PAC-WB \\
\hline Iodine number $(\mathrm{mg} / \mathrm{g}$ min $)$ & 900 \\
Ash content $(\%)$ & 6 max. \\
Moisture content $(\%)$ & $5 \mathrm{max}$. \\
Bulk density $\left(\mathrm{kg} / \mathrm{m}^{3}\right)$ & $290-390$ \\
Surface area $\left(\mathrm{m}^{2} / \mathrm{g}\right)$ & 882 \\
Nominal size & $80 \%$ min finer than 75 micron \\
Type & Wood based \\
Mean pore diameter $(\AA)$ & 30.61 \\
Micropore volumn $(\mathrm{cc} / \mathrm{g})$ & 0.34 \\
Mean diameter $(\mu \mathrm{m})$ & 19.71 \\
Product code & MD3545WB powder
\end{tabular}

\subsection{Molecular weight (MV) analysis}

Molecular weight (MW) distribution of dissolved organic matter was analysed prior to and after the pretreatment. High pressure size exclusion chromatography (HPSEC, Shimadze, Corp., Japan) with a SEC column (Protein-pak 125, Waters, Milford, USA) was used to determine the MW distributions of organics. The equipment was calibrated using the standards of MW of various polystyrene sulfonates (PSS: 210, $1800,4600,8000$ and 18000). The MW distribution results were analysed using the response $(\mathrm{mV})$ data of HPSEC with elapsed time.

\subsection{CFMF set-up}

The schematic diagram of the flat-sheet MF set-up used in this studay (Figure 1). The total membrane area was $3.24 \times 10^{-3} \mathrm{~m}^{2}$. The solution was circulated along the surface of the flat-plate membrane in the module at a crossflow velocity was $0.15 \mathrm{~m} / \mathrm{s}$. The Reynolds number and shear stress were 120 and $2.97 \mathrm{~Pa}$ respectively. PVDF (modified polyvinylidene difluoride) Minitan-S Microporous membranes sheets (with pore size of $0.45 \mu \mathrm{m}$ ) were used. In each experiment, new membrane was used to obtain reproducible results. The synthetic wastewater was delivered from a stock tank to the CFMF cell. The reject water and filtered water were returned to the feed tank. The initial transmembrane pressure was controlled by two valves and its variation during the filtration was monitored by using a pressure transducer at three points $\mathrm{P} 1$, P2 and Pf respectively. During the experiment, the filtration flux at each step was kept constant for at least 40 minutes for short-term experiments and 2 hours for long-term experiments. The TMP was calculated using the following equation:

$$
\mathrm{TMP}=(\mathrm{P} 1+\mathrm{P} 2) / 2-\mathrm{Pf}
$$




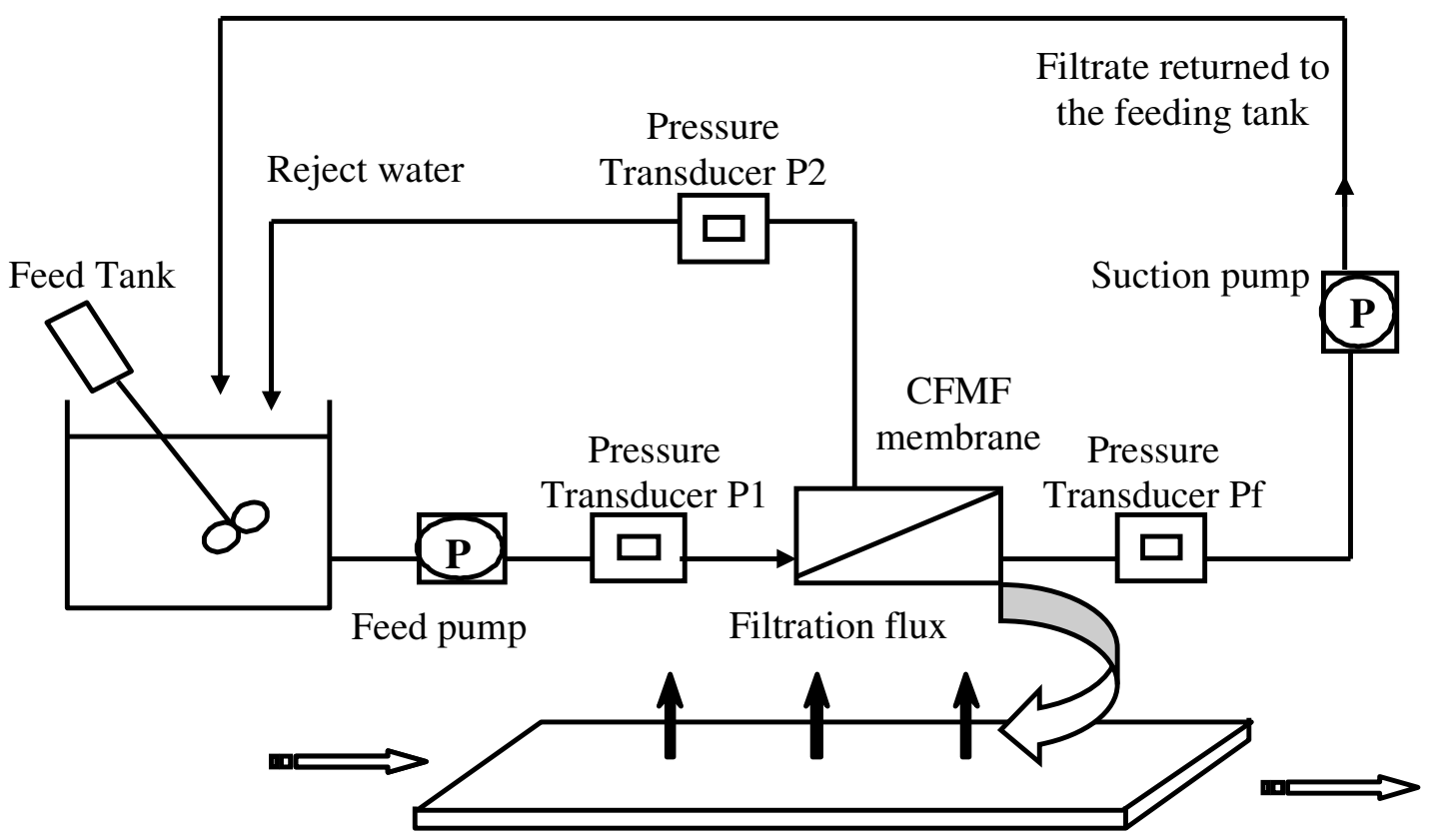

Figure 1 Critical flux experimental set-up

\section{Results and Discussion}

3.1 Molecular weight size distribution of synthetic wastewater after different pretreatments

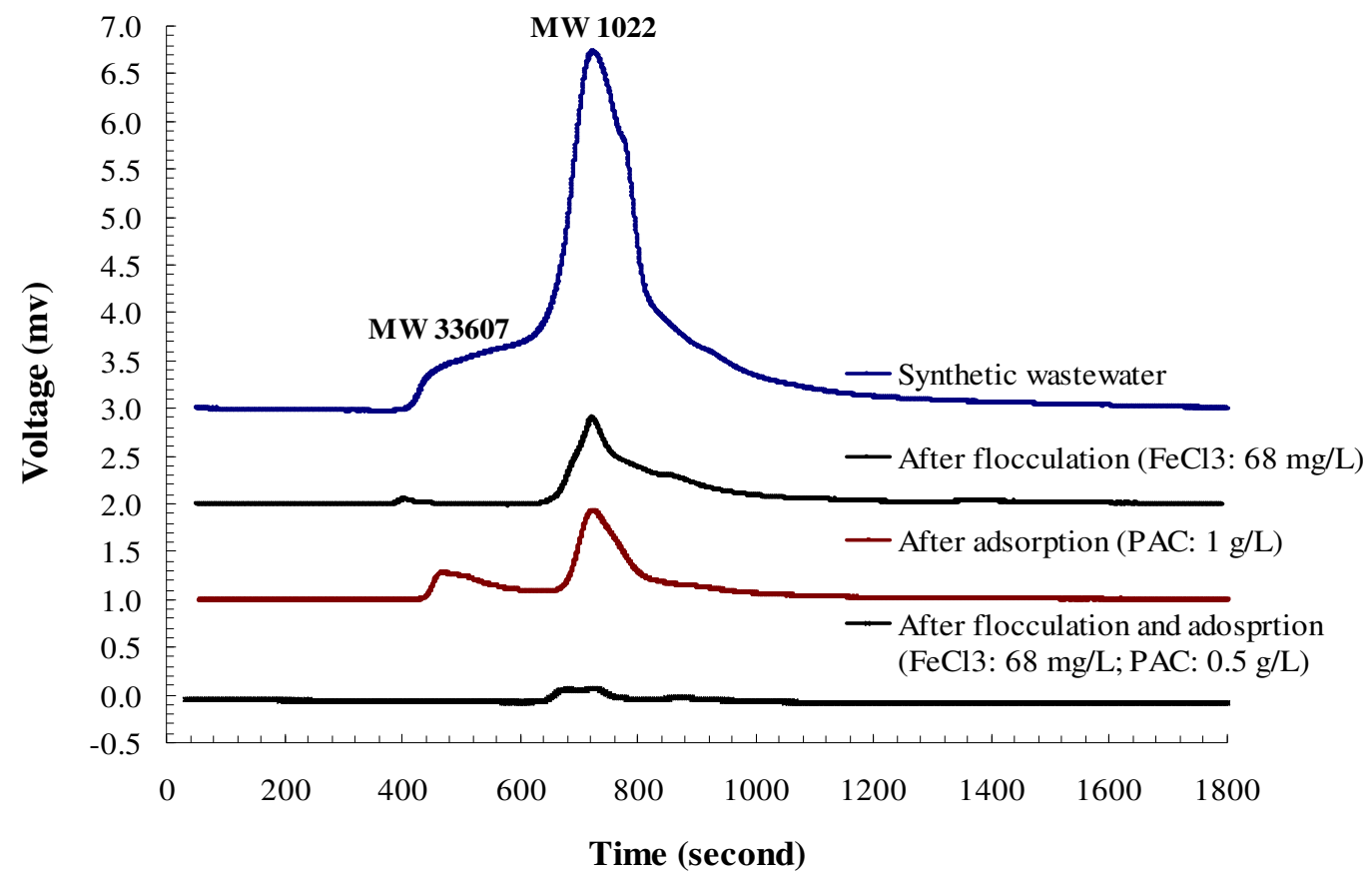

Figure 2 MW distribution of synthetic wastewater with different pretreatments 
The molecular weight (MW) of organic natter in the synthetic wastewater and the wastewater after different pretreatments were measured (Figure 2). The MW of the synthetic wastewater ranged from about 300 daltons to 45,000 daltons with the highest fraction of 900-1,200 daltons. The result indicated that flocculation removed the majority of large MW organics ranging from 2,000-45,000 daltons. It also removed a portion of the small molecular weight organics (500-1,800 daltons). This was mainly due to complexation mechanism of Fe. In addition, the adsorption of organic molecules onto Fe hydroxide was also responsible for small molecular weight organic matter removal. As adsorption for pretreatment of the synthetic wastewater, although adsorption removed 63\% DOC, the MW size distribution analysis showed that adsorption could not remove the large molecular weight part between 30,00060,000 daltons because adsorption was efficient in removing small MW organic matter. When flocculation together with adsorption was adopted as pretreatment, the process could remove the majority of the organics. Table 3 showed DOC removal efficiencies of synthetic wastewater after different pretreatments.

Table 3

Total organic carbon (TOC) removal efficiencies of synthetic wastewater after different pretreatments

\begin{tabular}{lcc}
\hline \multicolumn{1}{c}{ Experimental conditions } & TOC (mg/L) & TOC removal efficiency (\%) \\
\hline Synthetic wastewater only & 3.9869 & - \\
With flocculation & & 76.2 \\
$\left(\mathrm{FeCl}_{3}: 68 \mathrm{mg} / \mathrm{L}\right)$ & 0.9490 & 63.2 \\
With adsorption (PAC: $1 \mathrm{~g} / \mathrm{L})$ & 1.4672 & 80.4 \\
$\begin{array}{l}\text { With flocculation and adsorption } \\
\left(\mathrm{FeCl}_{3}: 68 \mathrm{mg} / \mathrm{L} ; \mathrm{PAC}: 0.5 \mathrm{~g} / \mathrm{L}\right)\end{array}$ & 0.7821 & \\
\hline
\end{tabular}

\subsection{Short-term critical flux experiments with synthetic wastewater}

Figures 3 and 4 show the variation of TMP value for constant filtration flux using the synthetic wastewater without and with preflocculation. Flocculation was operated in batch mode. Firstly, $68 \mathrm{mg} / \mathrm{L} \mathrm{FeCl}_{3}$ was added in wastewater, and then agitated for 21 minutes (rapid mixing of 1 minute at $100 \mathrm{rpm}$, slow mixing of 20 minutes at 30 $\mathrm{rpm}$ ). The flocculated wastewater was then settled for 20 mins prior to application of the supernatant to CFMF. The critical flux was only $100 \mathrm{~L} / \mathrm{m}^{2} . \mathrm{h}$ for the wastewater without preflocculation. It increased to $380 \mathrm{~L} / \mathrm{m}^{2} \mathrm{~h}$ when a pretreatment of flocculation was provided. These results confirm the importance of flocculation in enhancing the critical flux. The flocculation captured and agglomerated colloids, thereby reducing the membrane fouling by colloids. According to the results, flocculation had more considerable effect on the critical flux than adsorption for the synthetic wastewater investigated in this study (Figures 4 and 5).

The effect of adsorption and flocculation followed by adsorption as pretreatment on critical flux is shown in Figure 5 and 6 . Here, $2 \mathrm{~g} / \mathrm{L} \mathrm{PAC}$ was added in the wastewater and mixed for 1 hour, then the PAC was settled down for 15 hours. The supernatant was then sent through CFMF system. With the pretreatment of adsorption, the critical 
flux increased from $100 \mathrm{~L} / \mathrm{m}^{2}$.h to $240 \mathrm{~L} / \mathrm{m}^{2}$.h. However, with flocculation-adsorption as pretreatment, the critical flux increased more than 5 times (about $520 \mathrm{~L} / \mathrm{m}^{2}$.h) that of synthetic wastewater without pretreatment. This is due to the fact that flocculationadsorption was able to remove both large and small molecular weight organic matter while enhancing the filtration flux of CFMF and dissolved organic removal.

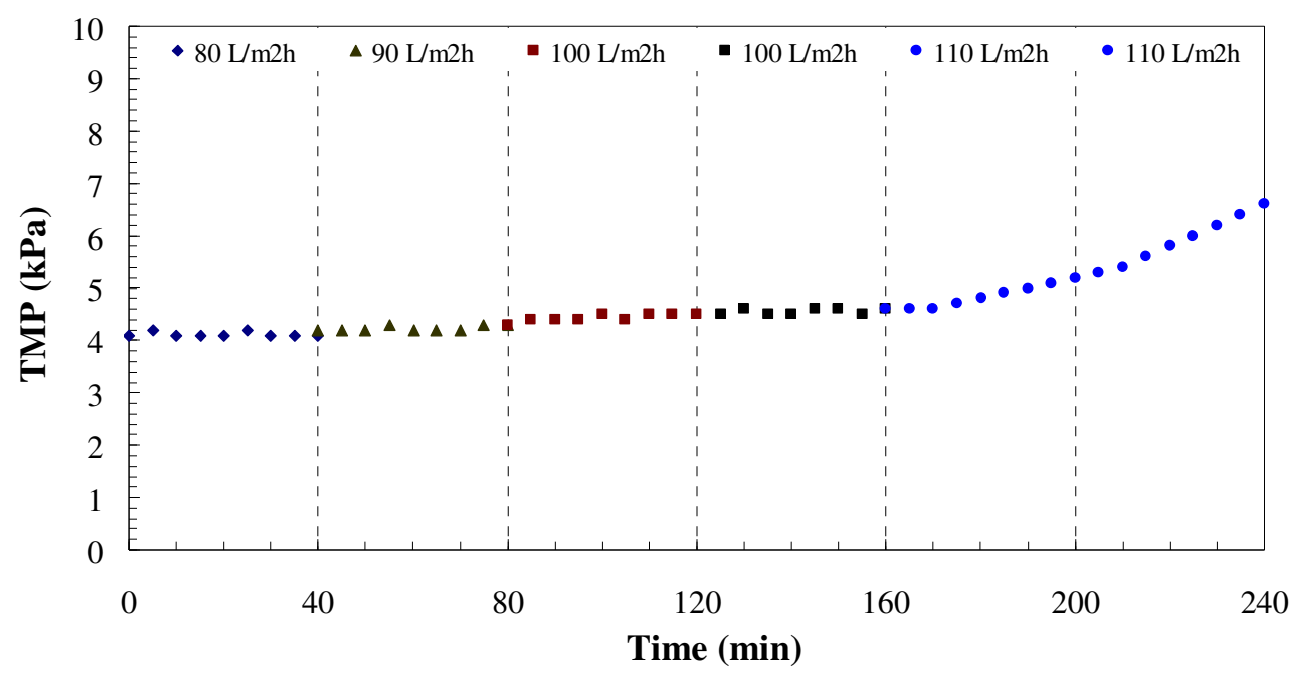

Figure 3 Constant filtration flux of synthetic wastewater (membrane pore size $0.45 \mu \mathrm{m}$; crossflow velocity $=0.15 \mathrm{~m} / \mathrm{s}$ )

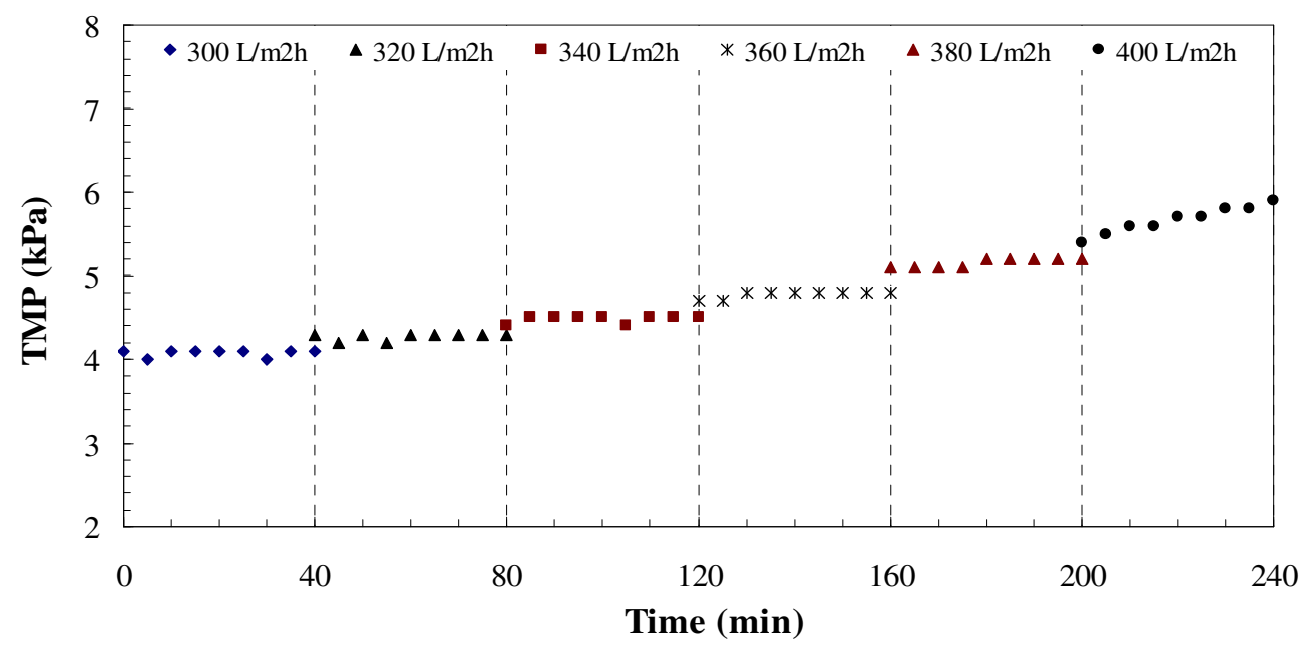

Figure 4 Constant filtration flux of synthetic wastewater with flocculation (membrane pore size $0.45 \mu \mathrm{m} ; \mathrm{FeCl}_{3}$ dose $=68 \mathrm{mg} / \mathrm{L}$; crossflow velocity $=0.15 \mathrm{~m} / \mathrm{s}$ ) 


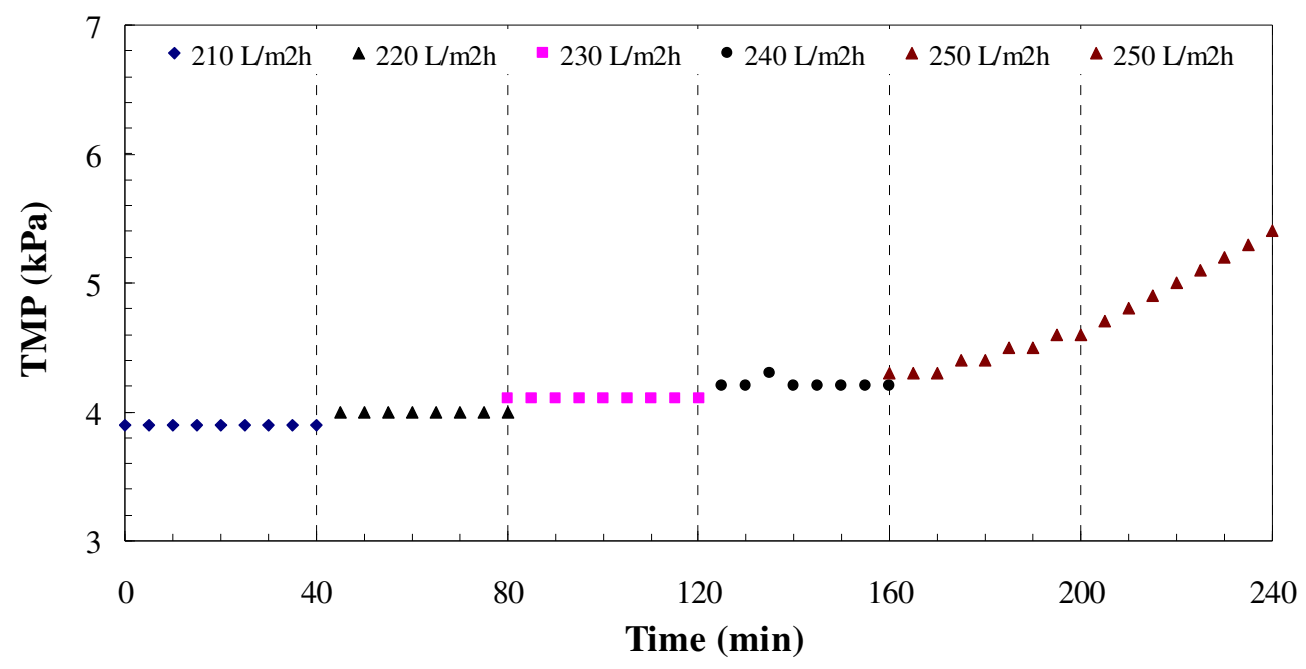

Figure 5 Constant filtration flux of synthetic wastewater with adsorption (membrane pore size $=0.45 \mu \mathrm{m} ;$ PAC dose $=2 \mathrm{~g} / \mathrm{L}$; crossflow velocity $=0.15 \mathrm{~m} / \mathrm{s}$ )

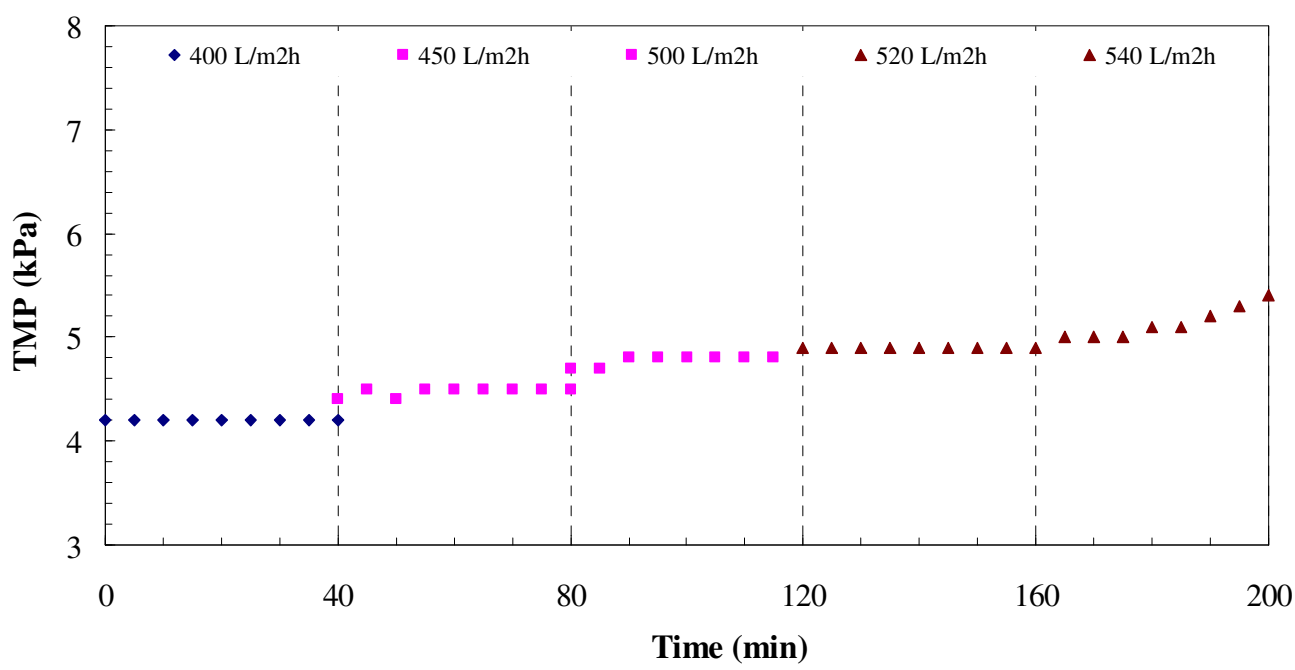

Figure 6 Constant filtration flux of synthetic wastewater with flocculation-adsorption (membrane pore size $=0.45 \mu \mathrm{m} ; \mathrm{PAC}$ dose $=2 \mathrm{~g} / \mathrm{L} ; \mathrm{FeCl}_{3}=68 \mathrm{mg} / \mathrm{L}$; crossflow velocity $=0.15 \mathrm{~m} / \mathrm{s}$ )

\subsection{Long-term critical flux experiments with synthetic wastewater}

In order to confirm the validity of critical flux in long-term, experiments were conducted based on the previous results of short-term experiments. The CFMF system was running at 0.8-1.2 range of short-term critical flux value with each constant flux for a period of 2 hours. Figures 7-10 show that the critical fluxes determined from long-term experiments were identical to those of short-term cases. However, the critical flux value of synthetic wastewater with the pretreatment of flocculationadsorption decreased in long-term test $\left(494 \mathrm{~L} / \mathrm{m}^{2} . \mathrm{h}\right)$ compared to short-term run $(520$ $\mathrm{L} / \mathrm{m}^{2}$.h) (Table 4). The TOC removal efficiencies with different pretreatment methods are present in Table 5 . 


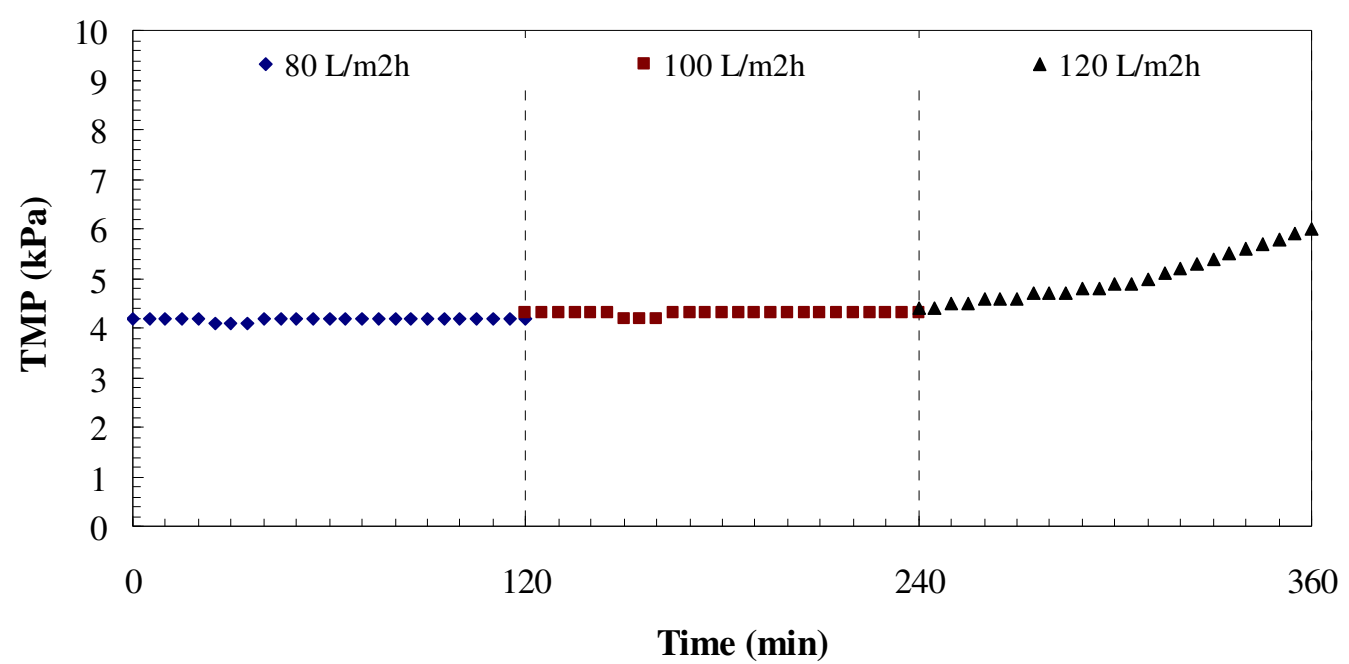

Figure 7 Constant filtration flux of synthetic wastewater (membrane pore size $0.45 \mu \mathrm{m}$; crossflow velocity $=0.15 \mathrm{~m} / \mathrm{s}$ )

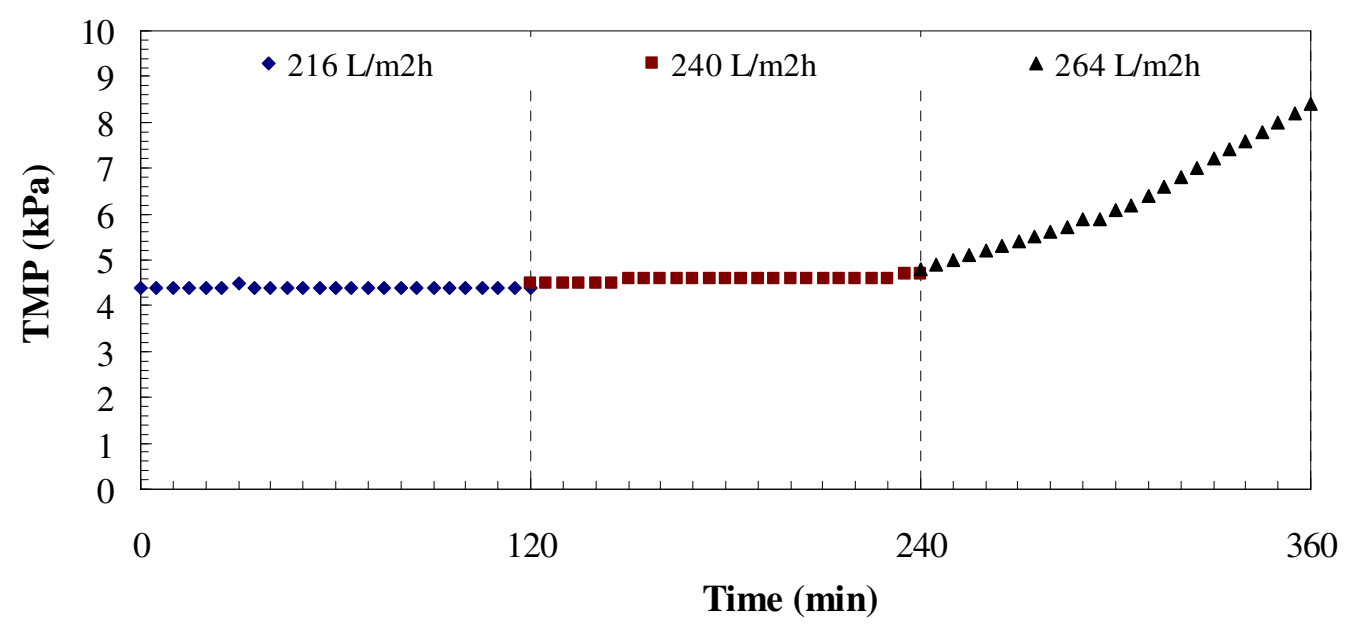

Figure 8 Constant filtration flux of synthetic wastewater with adsorption (membrane pore size $0.45 \mu \mathrm{m}$; PAC dose $=2 \mathrm{~g} / \mathrm{L}$; crossflow velocity $=0.15 \mathrm{~m} / \mathrm{s}$ )

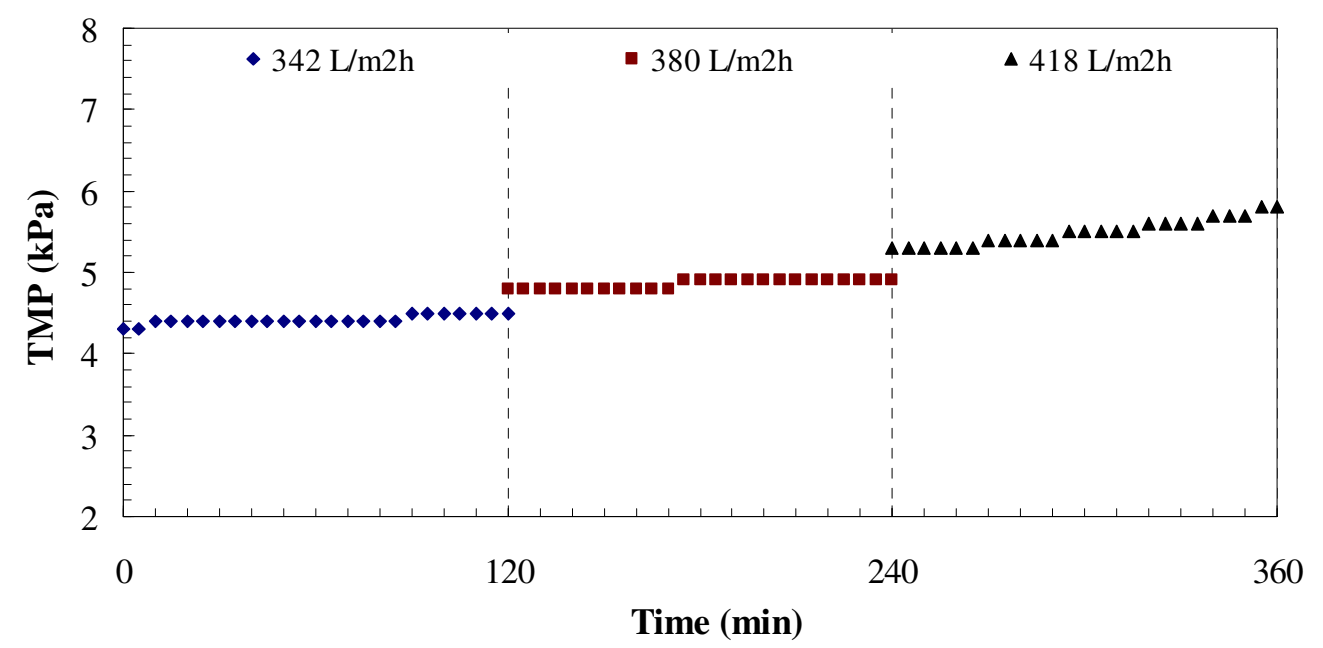


Figure 9 Constant filtration flux of synthetic wastewater with flocculation (membrane pore size $=0.45 \mu \mathrm{m} ; \mathrm{FeCl}_{3}=68 \mathrm{mg} / \mathrm{L}$; crossflow velocity $=0.15 \mathrm{~m} / \mathrm{s}$ )

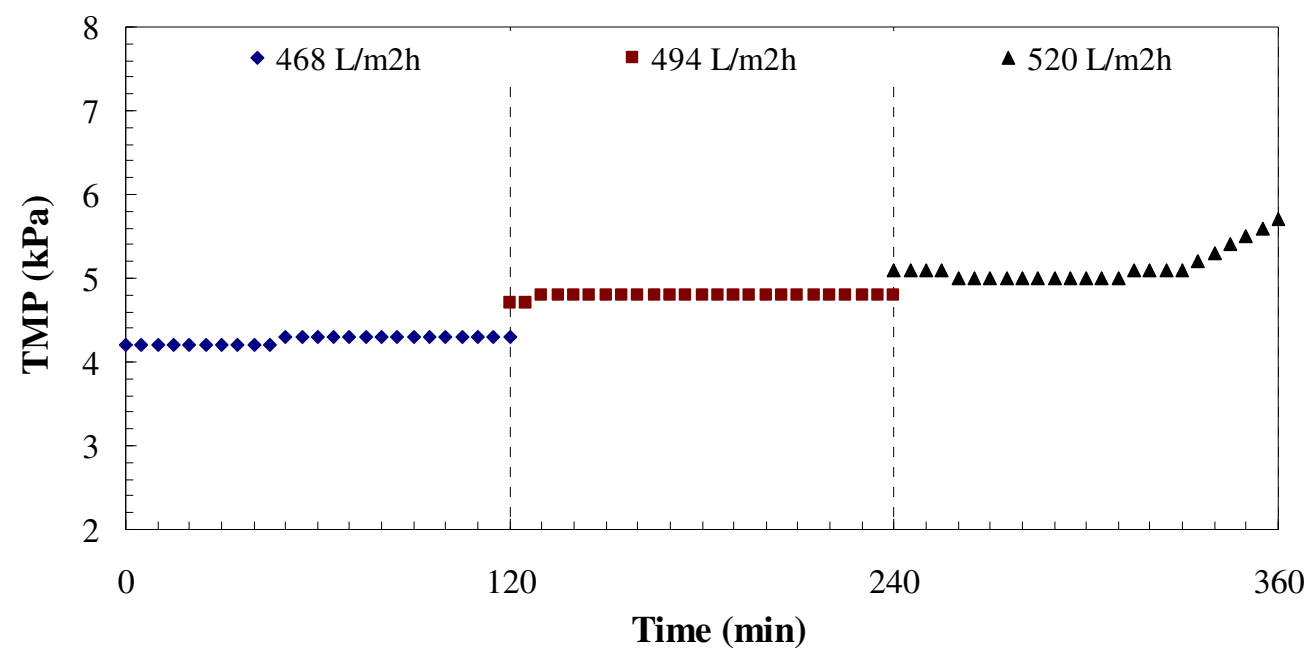

Figure 10 Constant filtration flux of synthetic wastewater with flocculation-adsorption (membrane pore size $=0.45 \mu \mathrm{m} ;$ PAC dose $=2 \mathrm{~g} / \mathrm{L} ; \mathrm{FeCl}_{3}=68 \mathrm{mg} / \mathrm{L}$; crossflow velocity $=0.15 \mathrm{~m} / \mathrm{s}$ )

Table 4

The critical flux of synthetic wastewater under different conditions

\begin{tabular}{|c|c|c|}
\hline Experimental conditions & $\begin{array}{c}\text { Short-term } \\
\text { critical flux } \\
\left(\mathrm{L} / \mathbf{m}^{2} . \mathbf{h}\right)\end{array}$ & $\begin{array}{c}\text { Long-term } \\
\text { critical flux } \\
\left(\mathrm{L} / \mathbf{m}^{2} . \mathbf{h}\right)\end{array}$ \\
\hline Synthetic wastewater & 100 & 100 \\
\hline $\begin{array}{l}\text { Wastewater after flocculation } \\
\left(\mathrm{FeCl}_{3}: 68 \mathrm{mg} / \mathrm{L}\right)\end{array}$ & 380 & 380 \\
\hline $\begin{array}{l}\text { Wastewater after adsorption } \\
\text { (PAC: } 2 \mathrm{~g} / \mathrm{L} \text { ) }\end{array}$ & 240 & 240 \\
\hline $\begin{array}{l}\text { Wastewater after flocculation and } \\
\text { adsorption }\left(\mathrm{FeCl}_{3}: 68 \mathrm{mg} / \mathrm{L} ; \text { PAC: } 2 \mathrm{~g} / \mathrm{L}\right)\end{array}$ & 520 & 494 \\
\hline
\end{tabular}

Table 5

TOC removal efficiencies (average) of synthetic wastewater after different pretreatments and CFMF (membrane pore size $=0.45 \mu \mathrm{m}$; crossflow velocity $=0.15$ $\mathrm{m} / \mathrm{s})$

\begin{tabular}{lc}
\hline \multicolumn{1}{c}{ Experimental conditions } & TOC removal efficiency (\%) \\
\hline After membrane & 8.79 \\
$\begin{array}{l}\text { After flocculation + membrane } \\
\left(\mathrm{FeCl}_{3}: 68 \mathrm{mg} / \mathrm{L}\right)\end{array}$ & 76.8 \\
\hline
\end{tabular}




\begin{tabular}{lc}
\hline After adsorption + membrane & 69.3 \\
(PAC: $2 \mathrm{~g} / \mathrm{L})$ & \\
After flocculation-adsorption + & \\
membrane $\left(\mathrm{FeCl}_{3}: 68 \mathrm{mg} / \mathrm{L} ; \mathrm{PAC}:\right.$ & 87.2 \\
$2 \mathrm{~g} / \mathrm{L})$ & \\
\hline
\end{tabular}

\section{Conclusions}

Flocculation with ferric chloride was efficient in removing large molecular weight organic matter from 30,000 to 60,000 daltons. It also could remove some of the small molecular weight organic compounds due to complexation mechanism. However, adsorption was not able to remove the large molecular weight organics $(30,000$ 60,000 daltons) significantly. When flocculation-adsorption was adopted as the pretreatment for synthetic wastewater, it removed of both large and small molecular weight organics (500-45,000 daltons).

Flocculation as pretreatment to CFMF was successful in improving the critical flux for the wastewater studied $\left(280 \mathrm{l} / \mathrm{m}^{2} . \mathrm{h}\right.$ improvement). The improvement in critical flux by adsorption of synthetic wastewater was less significant. With both flocculation and adsorption as pretreatment, the critical flux increased more than 5 times. There was no noticeable difference of the critical flux between long-term and short-term experiments in case of flocculation or adsorption as pretreatment but the pretreatment with flocculation-adsorption. These results confirm that the pretreatment by flocculation and/or adsorption is one of the key features to obtain simultaneously higher permeate flux and quasi-steady conditions of operation.

\section{Acknowledgment}

This research was funded by Australian Research Council (ARC) Discovery grant.

\section{References}

[1] R.W. Field, D. Wu, J.A. Howell and B.B. Gupta, Critical flux concept for microfiltration fouling. J. Mem. Sci., 100 (1995), 259-272.

[2] D.Y. Kwon and S. Vigneswaran, Influence of particle size and surface charge on critical flux of crossflow microfiltration. Wat. Sci. Tech., 38 (1998), 481- 488.

[3] S. Vigneswaran, D.Y. Kwon, H.H. Ngo and J.Y. Hu, Improvement of microfiltration performance in water treatment: is critical flux a viable solution?, Wat. Sci. Tech., 41 (2000), 309-315.

[4] H. Li, A.G. Fane, H.G.L. Coster and S. Vigneswaran, Direct observation of particle deposition on the membrane surface during crossflow microfiltration, J. Mem. Sci., 149 (1998), 83-97.

[5] D.Y. Kwon, Experimental investigation on critical flux in cross-flow microfiltration, PhD thesis, UTS, Sydney, 1998.

[6] R. Ben Aim, M. Mietton-Peuchot, S. Vigneswaran, K. Yamamoto and S. Boonthanon, A new process for water reuse: in line flocculation-crossflow filtration. Proceeding of water pollution control IAWPRC, 1988, 613-619. 
[7] G.T. Seo, S. Ohgaki, and Y. Suzuki, Sorption characteristics of biological powdered activated carbon in BPAC-MF (Biological powdered activated carbonmicrofiltration) system for refractory organic removal, Wat.Sci.Tech, 35(1997), 163-170.

[8] S. Kawamura, Integrated design and operation of water treatment facilities. John Wiley \& Sons, Inc, $2^{\text {nd }}$ ed., New York, 2000, pp.89-93. 